\title{
Developing metrics to characterize heat budgets in off-channel habitats, Willamette River, OR
}

C. E. Gombert ${ }^{1}$, S.T. Lancaster ${ }^{2}$, R. L. Flitcroft ${ }^{3}$, G. E. Grant ${ }^{3}$

${ }^{1}$ Water Resources Graduate Program, Oregon State University, ${ }^{2}$ College of Earth, Ocean, and Atmospheric Science, OSU, ${ }^{3}$ US Forest Service Pacific Northwest Research Station

Motivation

Fish Need to Cool Off, Too

The Willamette River exceeds regulatory temperature standards during late spring, summer, and early fall.

Cold water in side channels and alcoves provide ecosystem services critical for cold water fishes.

- Thermal regimes vary between and within off-channel habitat sites. Willamette River at Harrisburg, OR, USGS Gage 14166000

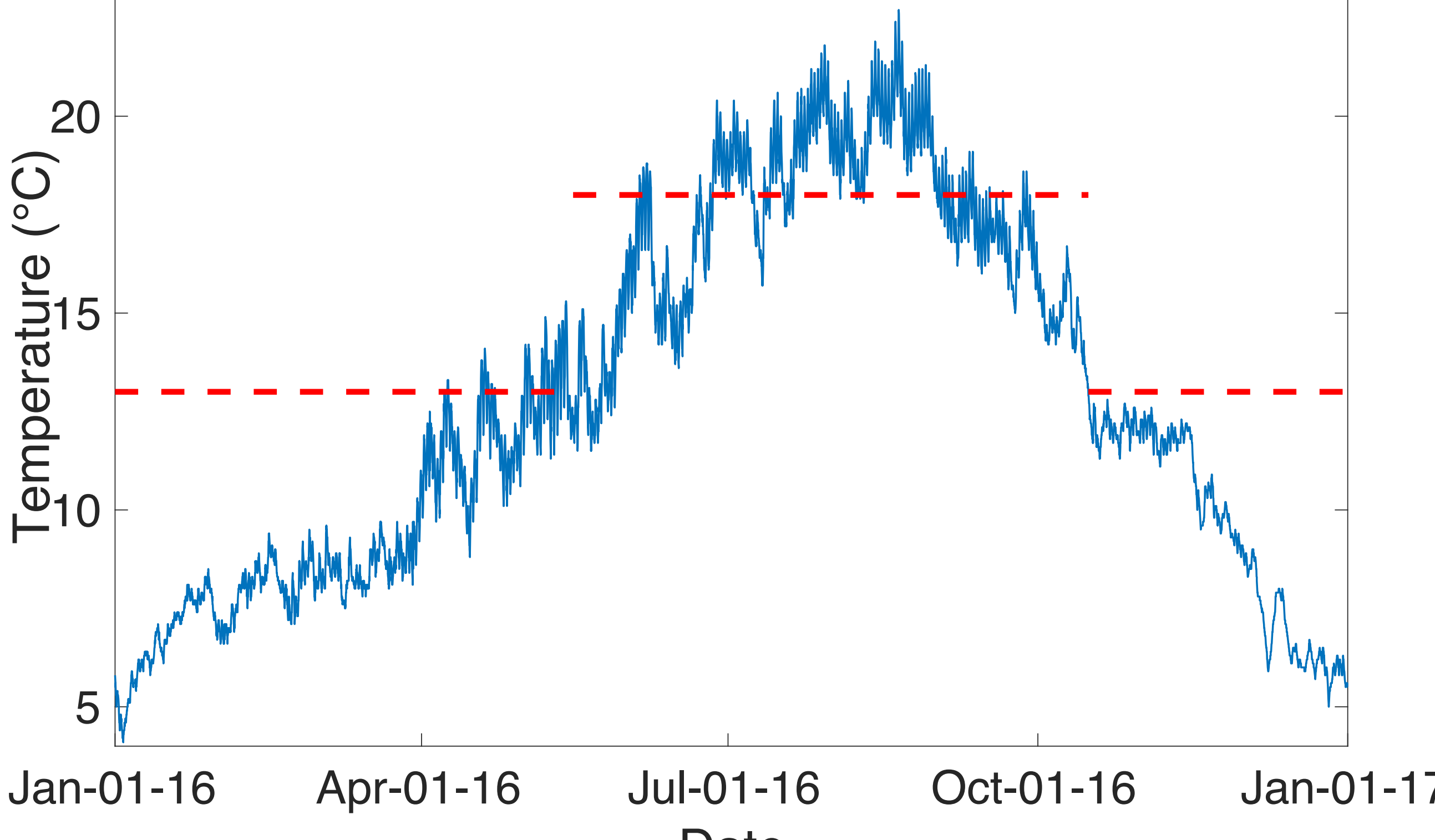

Jan-01-16 Apr-01-16 Jul-01-16 $\quad$ Oct-01-16 Jan-01-17

Figure 1. Dashed red lines indicate temperature standards for spawning $\left(13^{\circ} \mathrm{C}\right)$, and rearing and migration $\left(18^{\circ} \mathrm{C}\right)$ for Chinook salmon and cutthroat trout.

$$
\text { and }
$$

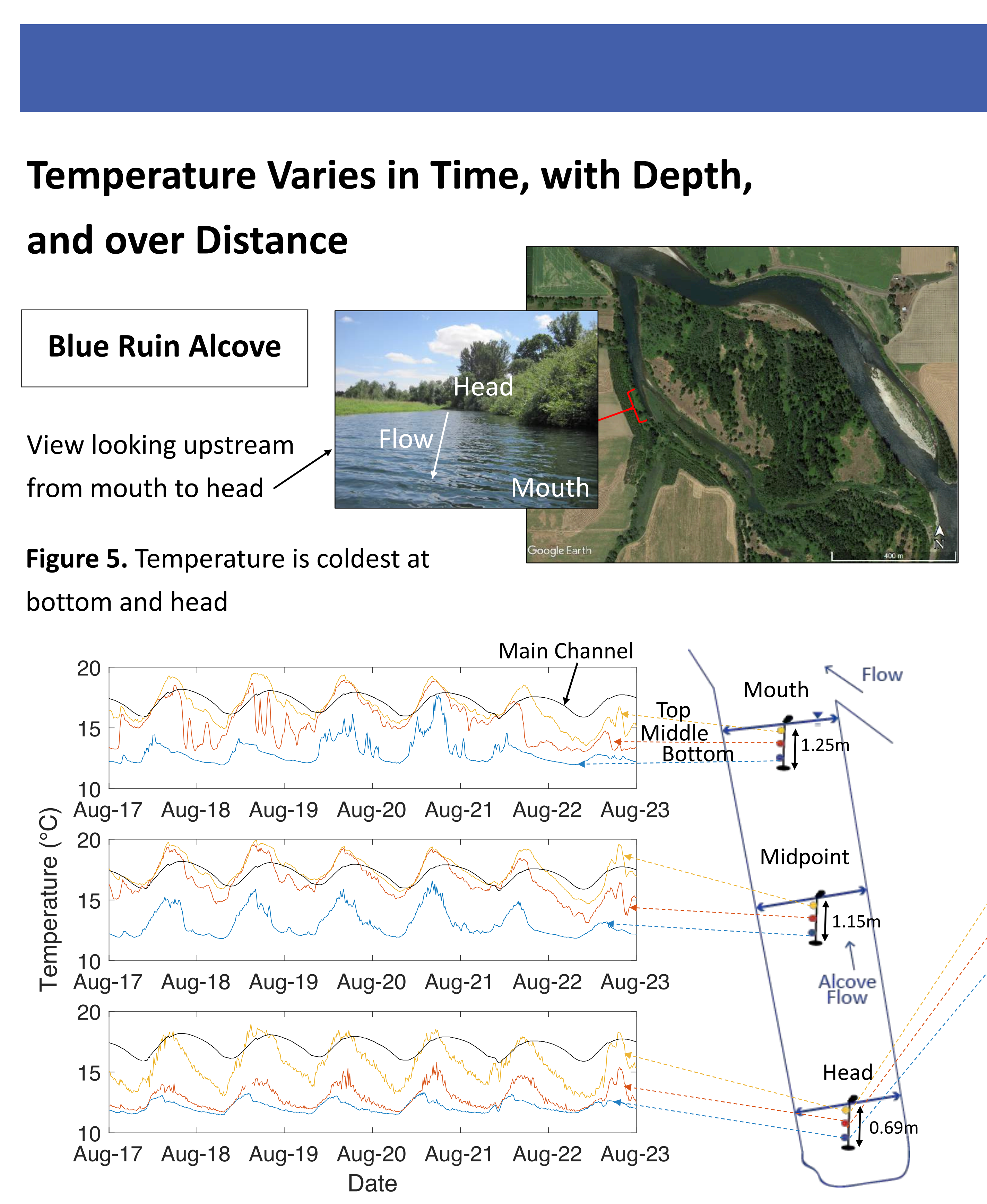

\section{Study Site and Methods}

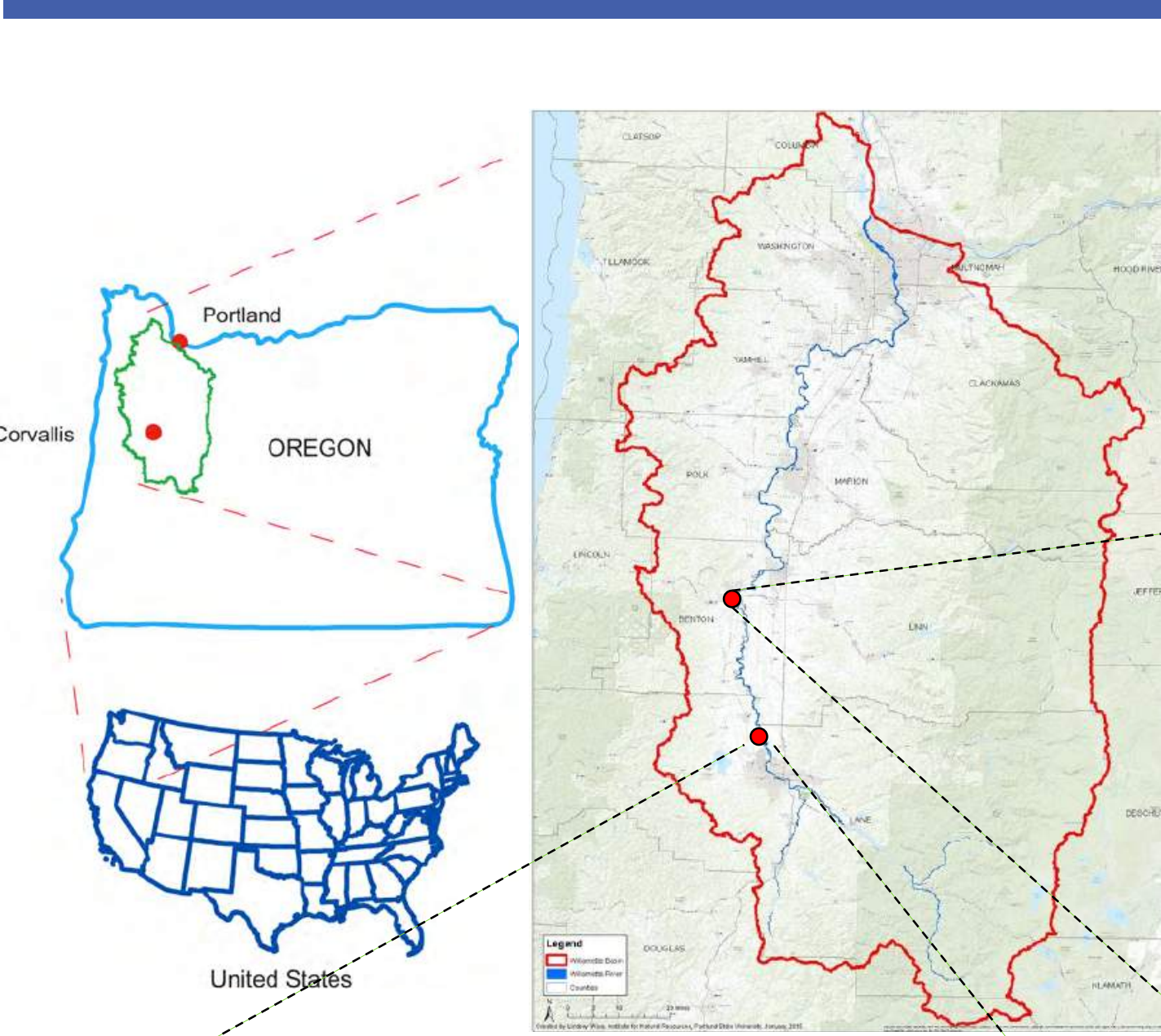

Upper Willamette River: the Most Dynamic Reach
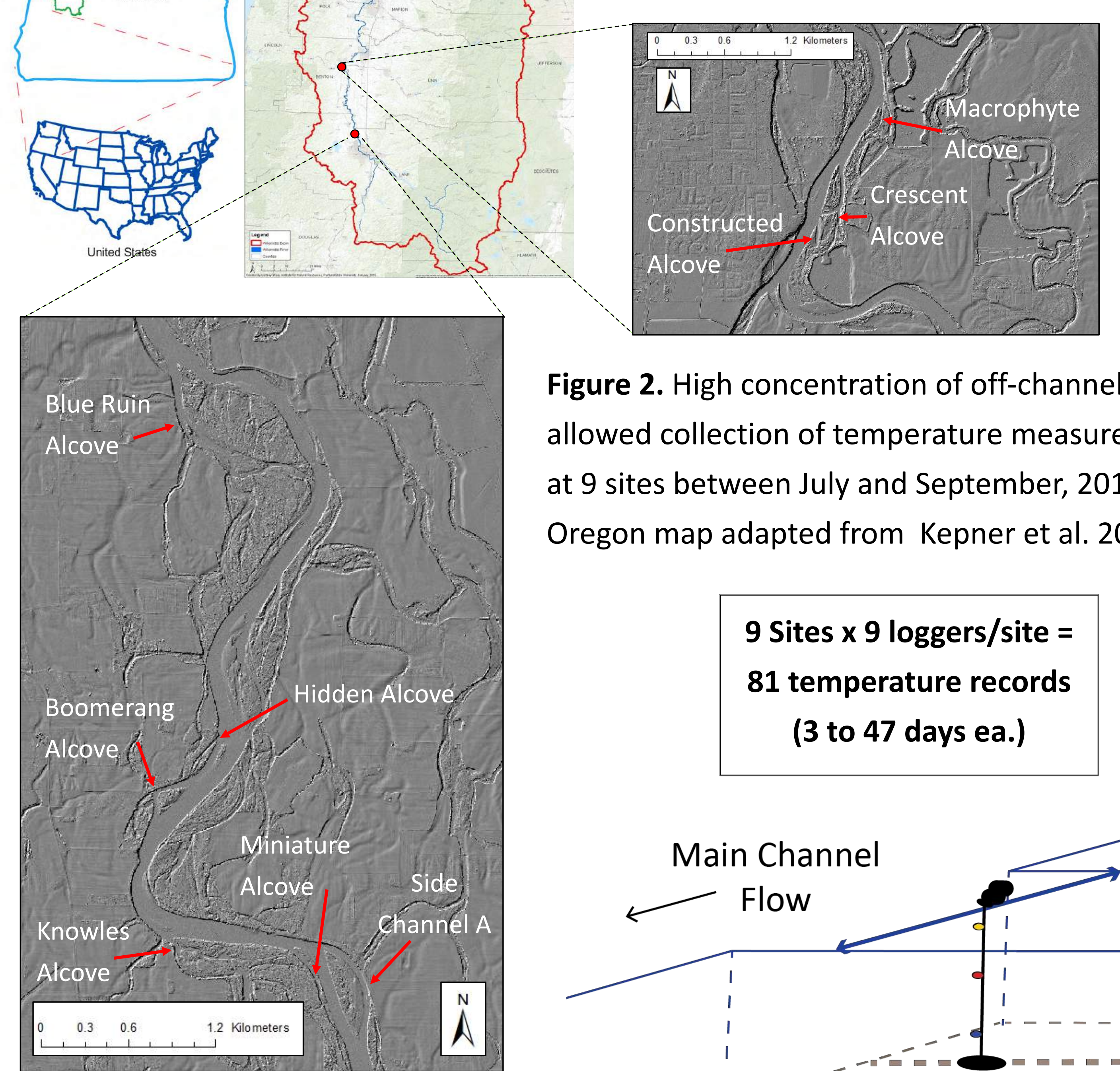
isure 2. High concentration of off-chanel sites (lites allowed collection of temperature measurements 9 sites between July and September, 2017. Oregon map adapted from Kepner et al. 2012 9 Sites $\times 9$ loggers $/$ site $=$ 81 temperature records (3 to 47 days ea.)

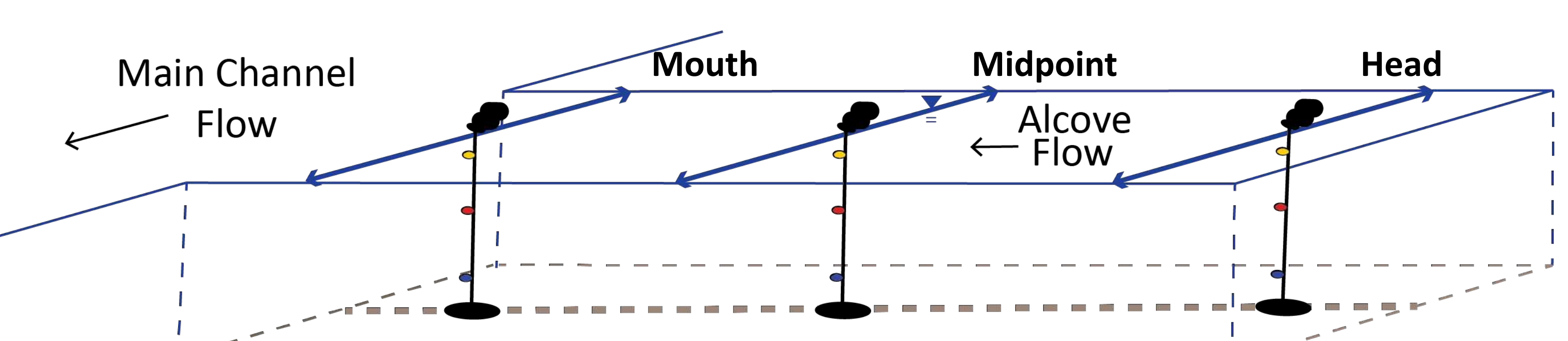

Results

Figure 6. Variations in temperature at alcove head may be explained by solar radiation, stage, and/or wind
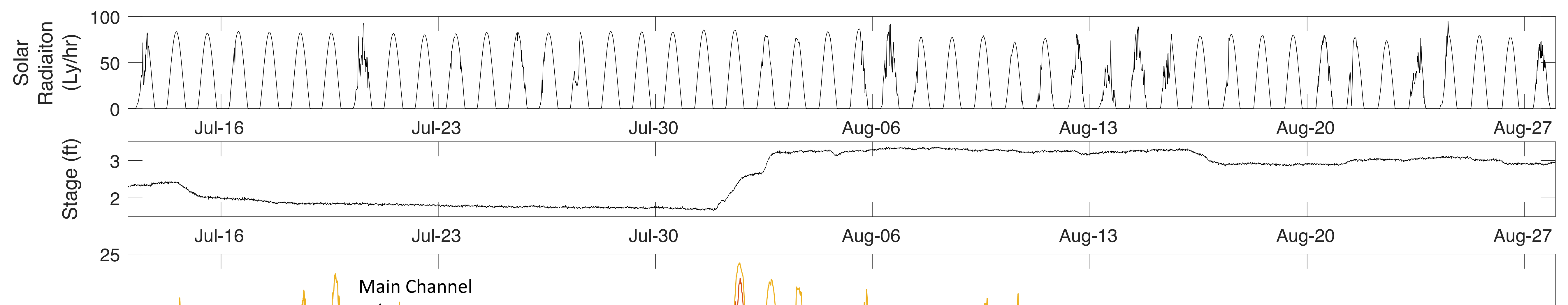

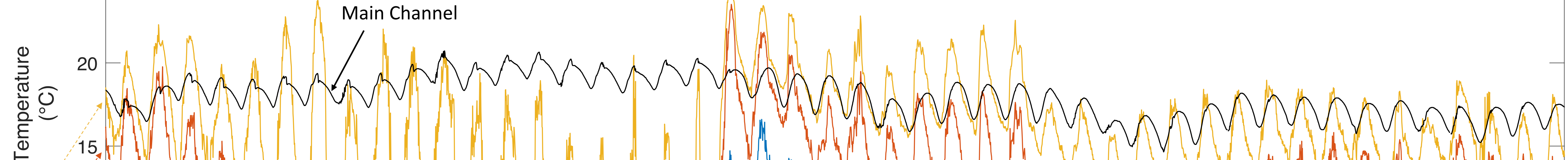

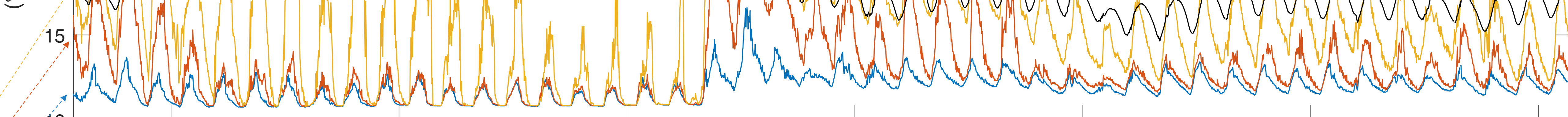

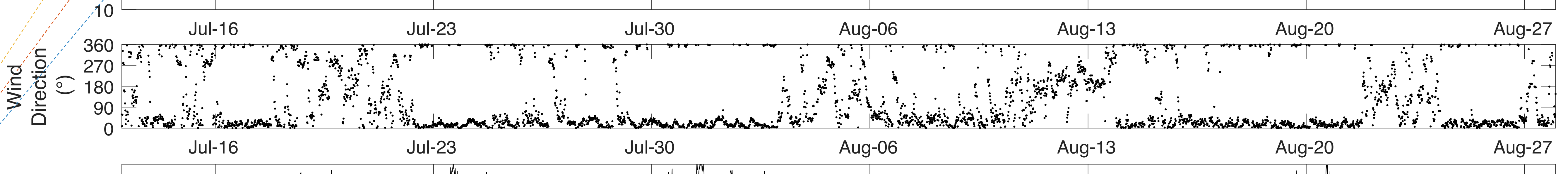
旁总总

\section{Emerging Stories}

Hierarchy of Control? Advection

Heat carried by flowing surface water dominates heat budgets in channel Insolation Stratification

Typically dominant among external Water near surface shades deeper heat sources and sinks water (Richardson trumps unless shaded Reynolds!)

Hyporheic

Supplies cool water, but typically overpowered by advection and insolation

Re $=\frac{\text { inertial forces }}{\text { viscous forces }}=\frac{u L}{v}$ $<i=\frac{\text { buoyancy term }}{\text { flow shear term }}=\frac{\frac{g}{\rho} \frac{\partial \rho}{\partial z}}{\left(\frac{\partial u}{\partial z}\right)^{2}}$

\section{Beavers!}

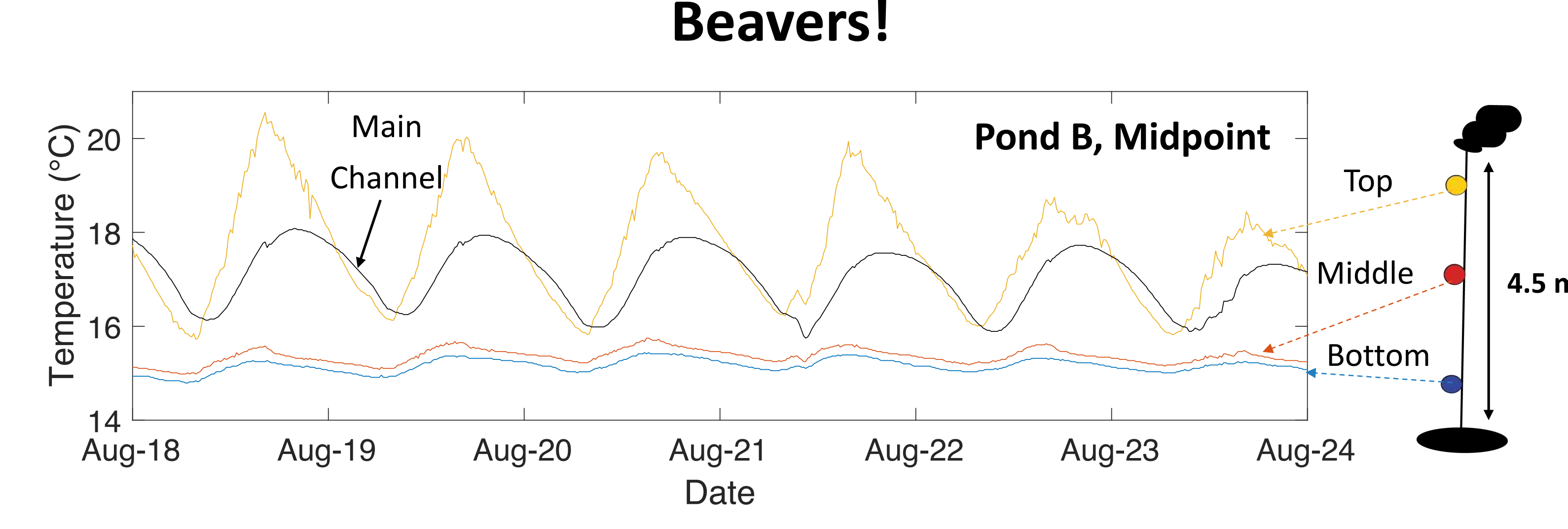

Figure 8. Cold water refuge: temperature in ponds is $2^{\circ} \mathrm{C}$ cooler than main channel

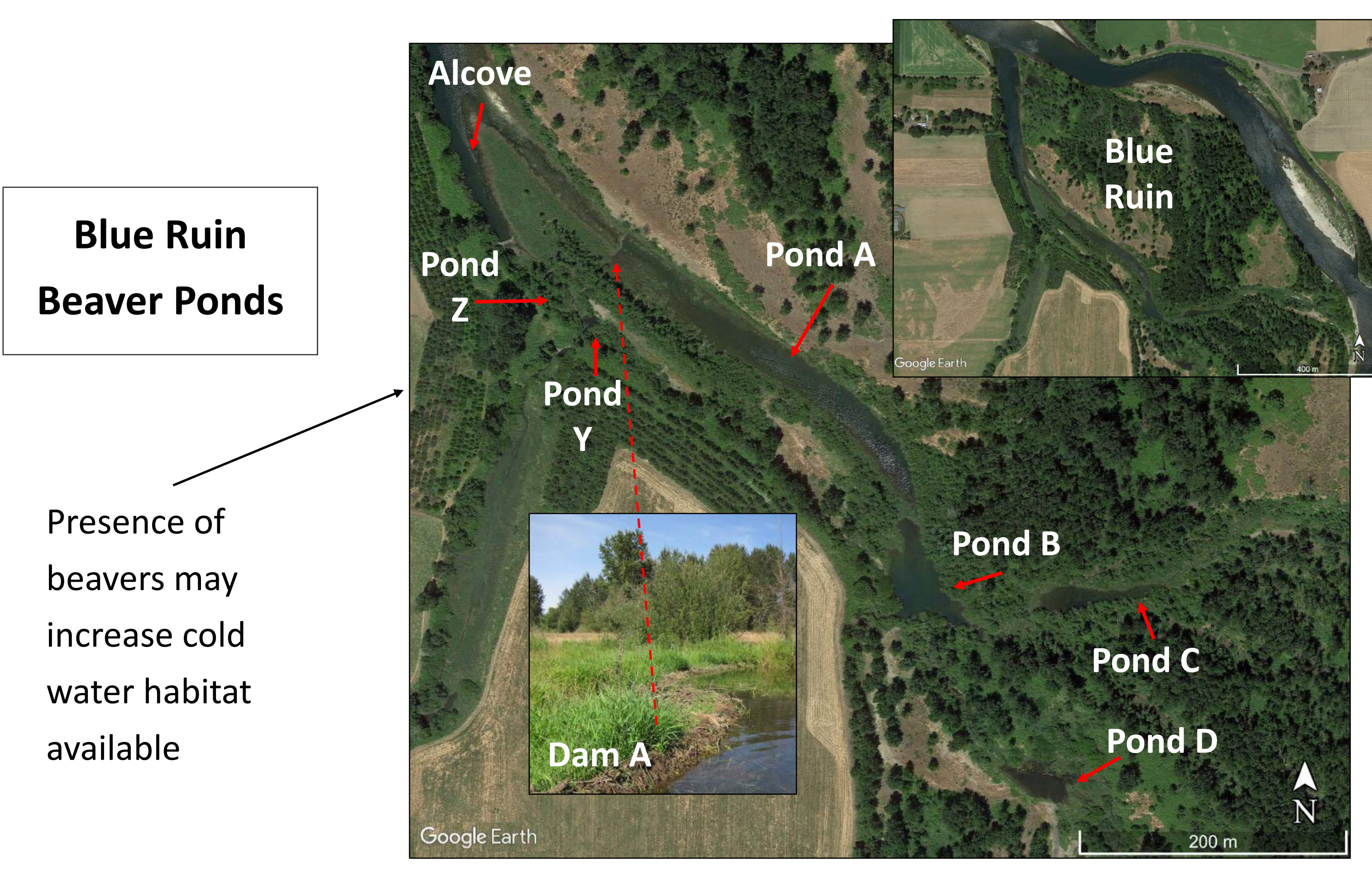

References

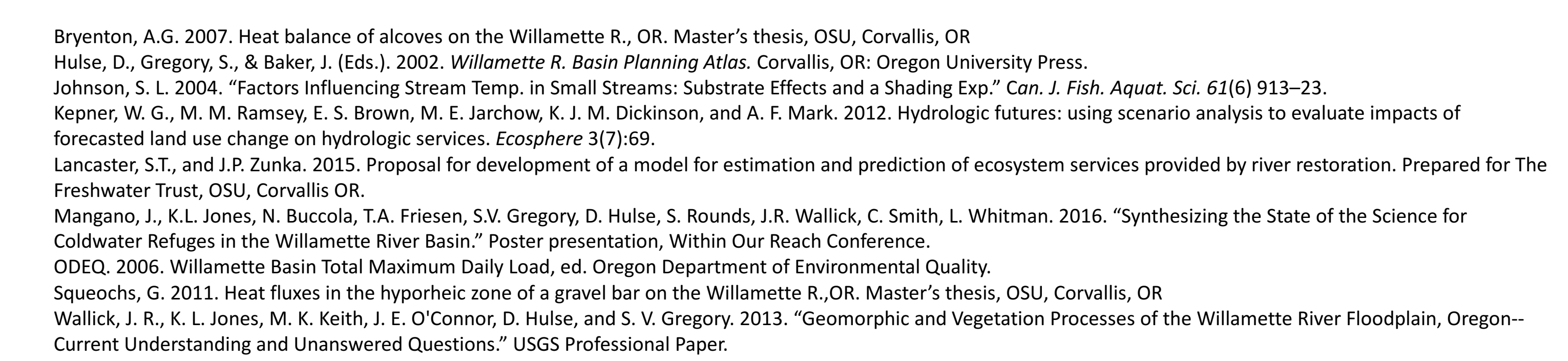

